\title{
SECOND CONTRIBUTION TO THE KNOWLEDGE OF THE LARVAE OF THE RAVINIINI (DIPTERA, SARCOPHAGIDAE) BASED ON OBSERVATIONS USING SCANNING ELECTRON MICROSCOPE
}

\author{
A.C. RIOS LEITE* \& H. DE SOUZA LOPES ** \\ * Departamento de Parasitologia, ICB, UliMG , Caixa Postal 2486, 31270 , Belo Horizonte, MG, Brasil \\ ${ }^{*}$ A cademia Brasileira de Ciencias, Caixa Postai 229, 20001, Rio de Janeiro, RJ, Brasil
}

First and second instar larvae of some Sarcophagidae (Diptera) of the tribe Raviniini are described based on observations with a scanning electron microscope.

Key words: Jarval instars - Ravinini Sarcophigidae - scanning electron microscope observations

A first contribution to the morphology of uterine larvae of Oxysarcodexia will be published in the "Revista Brasileira de Biologia" (Lopes \& Leite, in pres). Two species were studied, $O$. thornax (Walker) and $O$. confusa Lopes which present sinuous ribbons of festoons on pseudocephalon and conspicuous teeth on maxillae. These characters are evidently apomorphic ones, the former shared with Chaetoravinia and Andinoralinia (Lopes, 1962:172, Fig. 25); the latter observed, at least, in Chaetoravinia almeidai Lopes (Fig. 2).

In the present paper species of the genera Chaetoravinia. Ravinia, Oxyvinia and Oxysarcolexia are studied.

\section{MAIIRIAL. AND MITHODS}

Ralinia belforti (Prado \& Fonseca), Oxyvinia excisa (Lopes) and Oxysarcodexia confusa Lopes were obtained by dissection of females collected in Petrópolis, State of Rio de Janeiro, the first instar larvae of Chaetorania almeidai Lopes was preserved in the collection of the National Museum ("Museu Nacional"), in ethanol $70 \%$. The first referred species were killed in $80 \%$ water; all specimens were dehydrated in $90 \%$ and $100 \%$ ethanol, critical point dried in $\mathrm{CO}_{2}$ coated gold and photographed using a Novascan-30-Zeiss scanning electron microscope of the Department of Morphology, Institute of Biological Sciences. Federal University of Minas Gerais. Belo Horizonte.

\section{RL:SUL.TS}

The Raviniini are separated from the other Sarcophagidae by the following apomorphic characters: Frontal bristles not divergent anteriorly; penis entire or having a short theca (Oxyvinia); first instar larvae with conspicuous

Partially uupported by "Conselho Nacional de Dexenvolviment. Científico e Tecnológico" - CNPq.

Received September 9, 1986.

Accepted December 29, 1986. festoons on pseudocephalon and densely pilose posterior stigmatical region. The ribbon of festoons was hitherto observed, in addition to the Raviini, only in the species of Aulacophyto (Lopes, 1978: 761, Figs. 21, 37, 52), genus considered, at present, in the Microcerellini.

Based on the present study, the characterization of the genera of Raviniini shall be completed as follows:

Ravinia Robineau Desvoidy, 1863 (typo species: Musca pernix Harris) (14 American species)). First instar larvae with almost straight ribbon of festoons (Fig. 10), maxillae without teeth (Fig. 11); fifth sternite of males with parallel spinous margins of median slit; apical plate and theca united to paraphallus, ventralia small, slender; lateral plates stronger than ventralia; females with conspicuous tergite VIII; sternite IX broad.

Andinoravinia Townsend, 1917 (type species: rufipes Townsend) (one species). First instar larvae with sinuous ribbon of festoons (Fig. 1); R1 hairy; male fifth sternite and penis like those of Ravinia but ventralia more developed than lateral plates; female genital sclerites like those of Ravinia, mostly with strong sternite VIII.

Oxyvinia Dodge, 1966 (type species:piliventris Dodge) (8 species). First instar larvae with almost straight ribbon of festoons (Fig- 16), each festoon narrowed on middle (Fig. 21), a convex band immediatly after the festoons; second instar larvae with ventral side of pseudocephalon showing an anterior region with irregular plates and striated atrium, the striae presenting conspicuous dentations (Fig. 28) and exceeding pilose margins of spiracular cavity (Fig. 29); male fifth stemite with spinous parallel margins of median slit; female mostly with reduced tergite VIII.

Oxysarcodexia Townsend, 1917 (type species: Sarcophaga peltata Aldrich) (71 species). First instar larvae with sinuous ribbon of 
festoons and conspicuous teeth on maxillae; second instar larvae very similar to these of Oxyvinia (Figs. 30, 31), first thoracic segment, ventrally, with plates bearing large spines (Fig. 33). Male with divergent internal margins of fifth sternite; penis without lateral plates, ventralia always composed of a median sclerotized arm and apical lobes, mostly spinous. Female with, at most, vestigial tergite VIII; sternite IX always reduced to a median small plate.

Hybopygia Enderlein, 1928 (type species: Sarcophaga varia (Walker) (3 species). Very similar to Oxysarcodexia but sternite IX broad; larvae unknown.

Apelophyla Hall, 1938 (type species: marina Hall) (1 species). Very similar to Hybopygia. with peculiar apex of penis. Female and larvae unknown.

Xarcophaga Dodge, 1968 (type species: xon Dodge) (4 species). Very similar to Oxysarcodexia including the structure of female sternite IX, but ventralia of penis very much different. Larvae unknown.
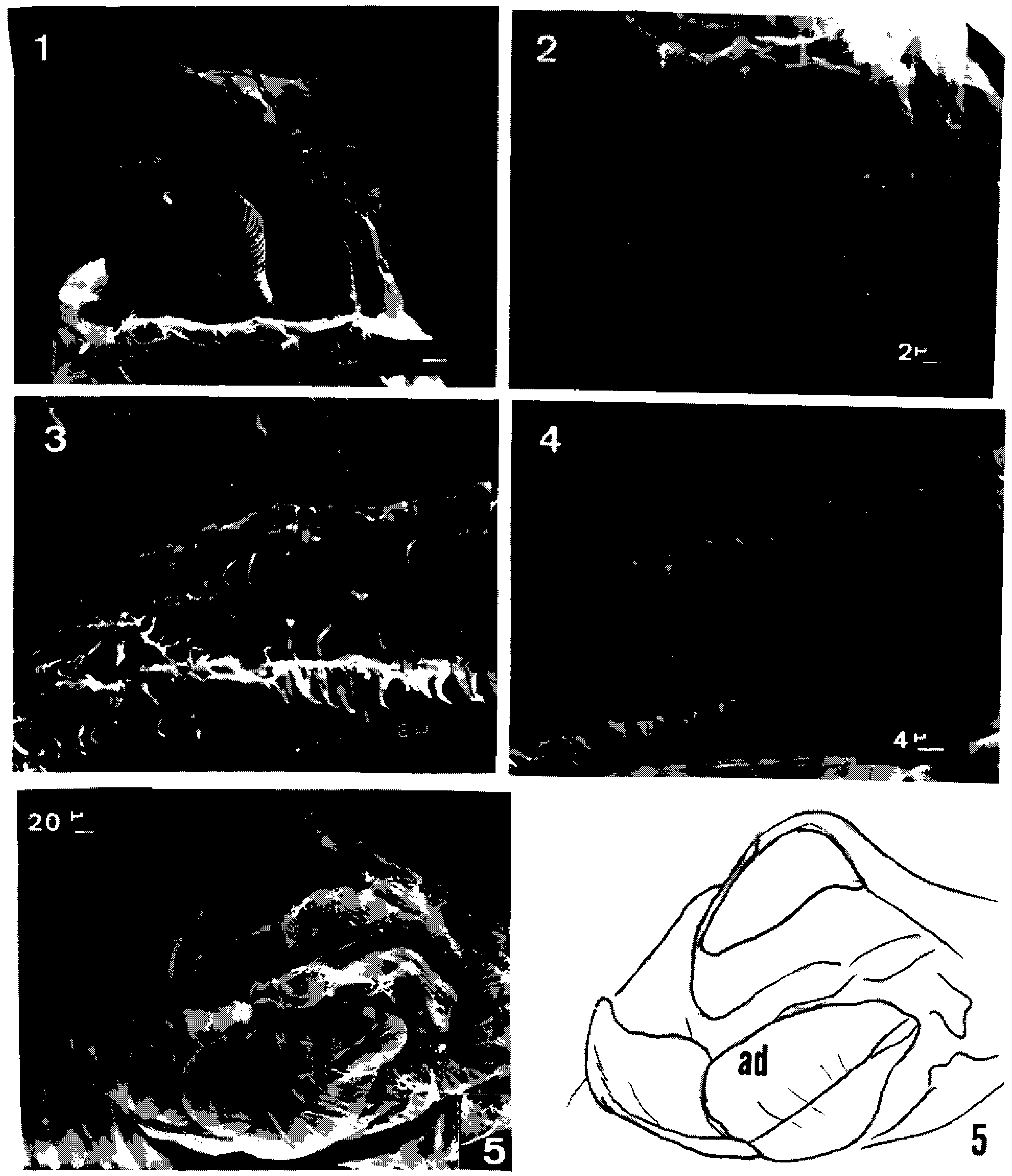

Chaetoravinia almeidai Lopes, first instar larva. Fïg. 1: anterior end., ventral side I'ig. 2: maxillae liig. 3: second thoracic segment, spines of anterior margin. Fig. 4: spines of anterior margin of sixth (above) and anterior margin of seventh abdominal segments. Fig. 5 : posterior end (ad = perianal pads). 


\section{Genus Chaetoravinia Townsend, 1917}

The uterine larvae of the species of this genus show sinuous ribbon of festoons with somewhat contiguous branches: C. almeidai Lopes (Fig. 1, 7), or slightly curved: $C$. advena (Walker) (Fig. 6); the festoons are, like those of the species of Oxysarcodexia, situated near the margin of first thoracic segment. Some authors (Downes in Stone et al., 1965) considered Chaetoravinia in the synonymy of Ravinia, based on external characters of the males. However, the structure of the penis is very much different and the above referred characters of the first instar larvae demonstrate that Chaetoravinia is more closely related to Oxysarcodexia than to Ravinia. The small teeth on the maxillae present mostly on the internal surface of $C$. almeidai Lopes (Fig. 2) is another apomorphy shared by the species of Chaetoravinia and Oxysarcodexia; the mandible in the species of the genera is mostly membranous (Fig. 9).

\section{Chaetoravinia almeidai Lopes, 1946}

(Figs. 1 to 5,7 to 9 )

Firtst instar larvae showing ribbon of festoons on pseudocephalon with almost contiguous branches, the festoons slender (Figs. 1,7
8); maxillae with conspicuous teeth on internal surface, not reaching the extremity (Fig. 2). First thoracic segment with backwards directed spines with flamentous apices on anterior margin of the segment; second (Fig. 3) and third segments with similar but more numerous spines, the posterior ones contiguous, serrate. Thoracic segments, on ventral surface, with a pair of trilobate sensillae like surface, with a pair of trilobate sensillae like these described for Oxysarcodexia confusa Lopes (Lopes \& Leite, in press, Fig. 6); on the outside for these sensillae, there are papiliform structures. First abdominal segment with backwards directed spines showing slender apices on anterior margins and posterior spines anteriorly directed. Second to seven segments with slender spines but increasing in number and length, having also short spines in the posterior series on anterior margin (Fig. 4). Eight segment with numerous long hairs mostly on the borders of the spiracular cavity and with circunspiracular and anal tubercles reduced; perianal pads large (Fig. 5); three to five points were seen in the hairs near spirracular openings. Two uterine larvae were examined, culture nr. 1098 from a female collected in Angra dos Reis, State of Rio de Janeiro, in the collection of the "Museu Nacional".
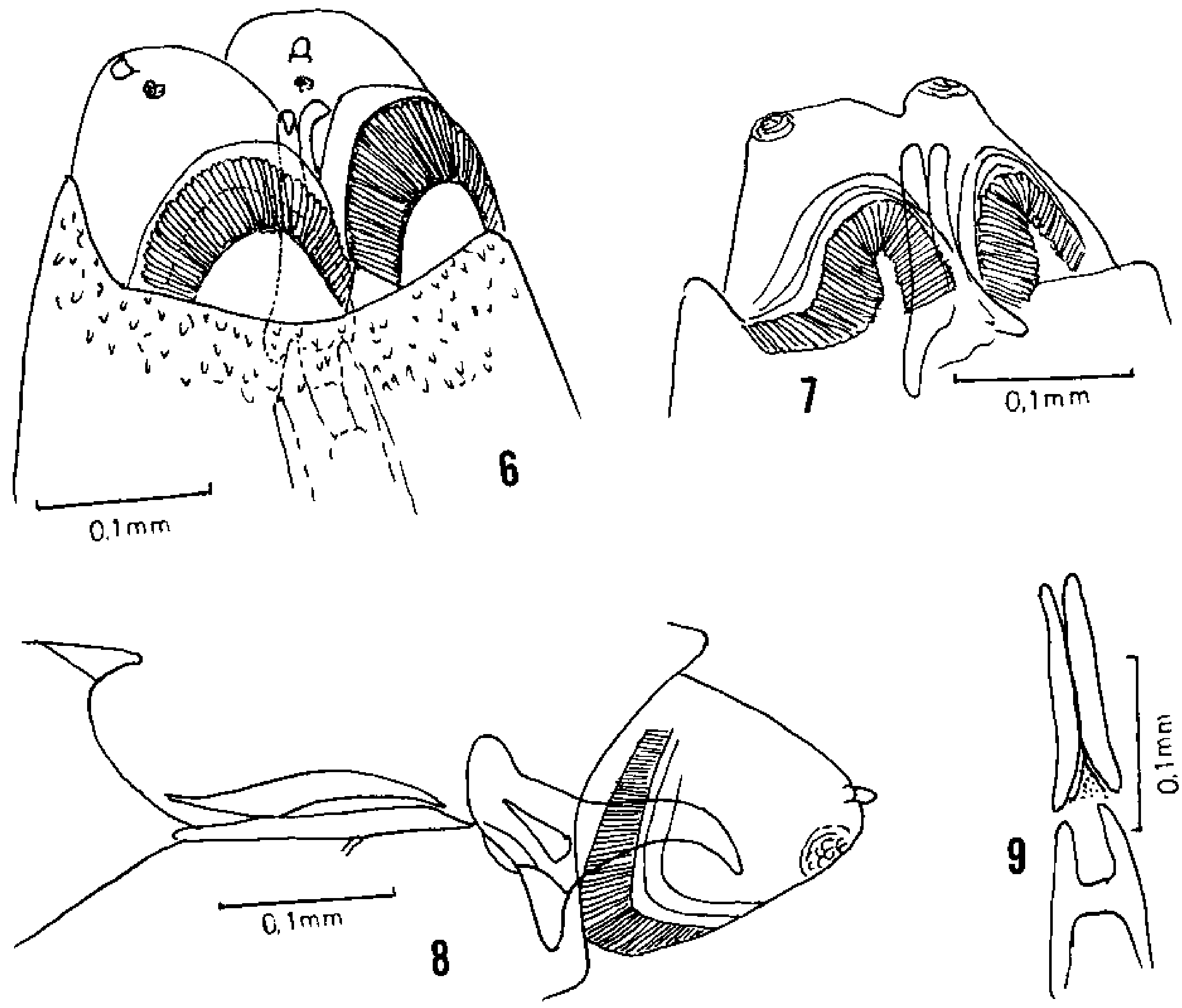

Chactoravinia advena (Walker), dissected from dry specimen, first instar larva. Irig. 6: anterior end, ventral view. Chaetoravinia almeidai Lopes, first instar larva from dry female. Fig. 7 : anterior end, ventral view. Fig. 8: idem, lateral view. l:ig. 9 : cephalo-pharyngeal skele ton, dorsal view. 
Chaetoravina advena (Walkear, 1852) (Fig. 6)

From dissection of a dry female collected in Castro, State of Paraná, Brazil, uterine larvae with largely curved ribbon of festoons (Fig. 6) were obtained.

Ravinia belforti (Prado \& Fonseca, 1932) (Figs. 10 to 15 )

The uterine larvae obtained from females collected in Petrópolis, State of Rio de Janeiro, present pseudocephalon with aimost straight, only a little curved ribbon of festoons, conspicuous furrows, with well limited margins, siting apically to the festoons; first thoracic segment with large median ventral spinous region extended over the sides as a slender band (Fig. 10): maxillae without teeth but showing delicate pits and ridges (Fig. 11): the spines of ventral side of the anterior margin of first thoracic segment are directed posteriorly and each plate is composed of two to four spines (Fig. 12); second and third segments with few anterior spines. The pair of sensorial pits containing trilobate sensilla found in the species of
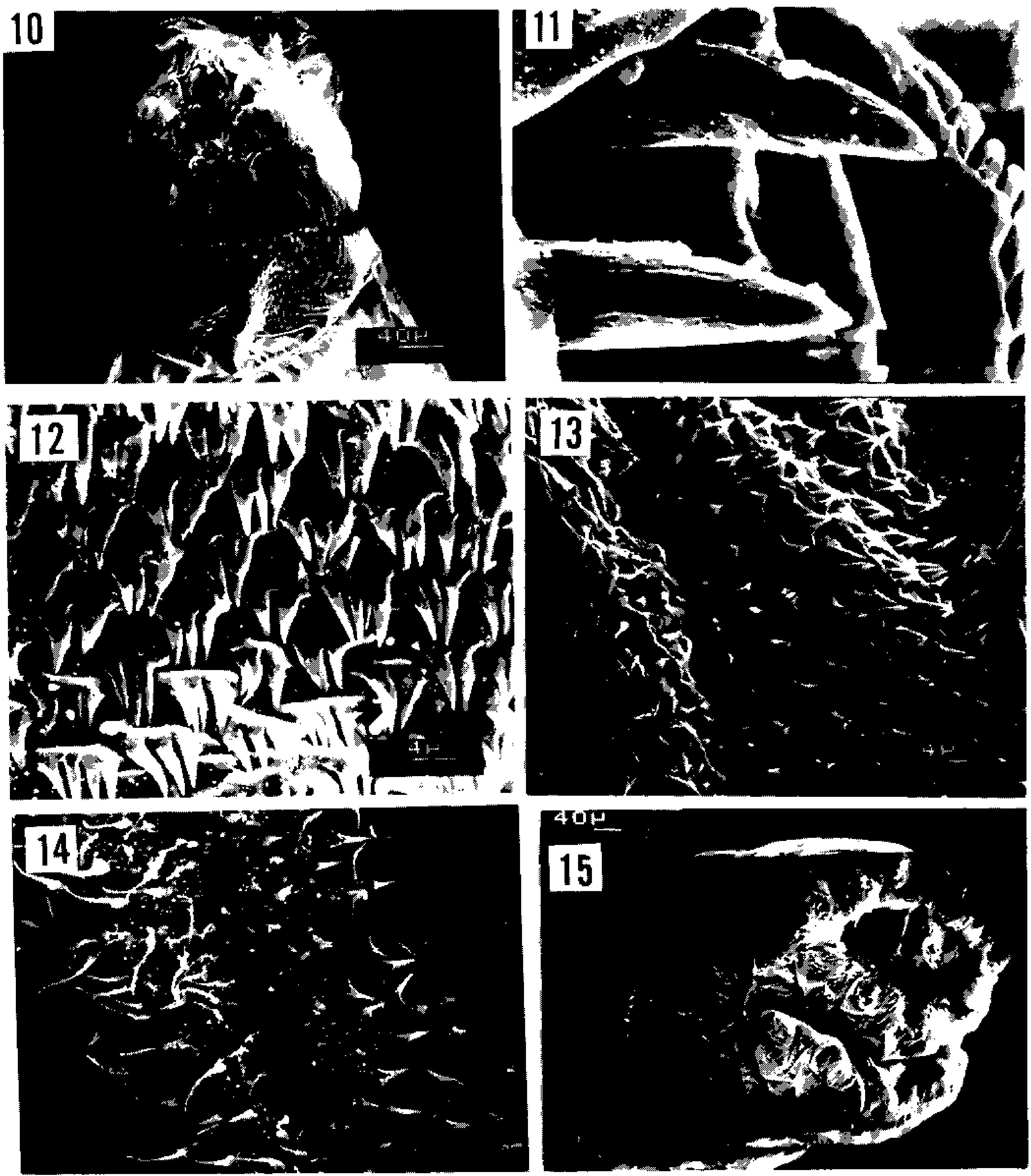

Ravinia belforti (Prado \& Fonseca), first instar larva. Fig. 10 : anterior end, ventral view. Fig. 11 : maxiłlac. Fig. 12: ventral spines of anterior margin of first thoracic segment. Fig. 13: spines of posterior matyin of third (left) and spines of anterior margin of fourth abdominal segments (right). lig. 14:spines of posterior margin of sixth (left) and anterior margin of seventh segments (right). Fig. 15 : posterior end. 
Oxysarcodexia and pits bearing elongate process near lateral side of the thoracic segment are also observed in $R$. belforti: the pairs of trilobate sensillae are more far one from another on the third segment. Spines of the anterior margins of the abdominal segments, directed backwards, are more slender and scattered from first to last segments; spines of the posterior margins of the abdominal segments are directed anteriorly. Posterior margin of third segment with short, scatterd spines, anterior margin of fourth segment with small spines near margin and more elongated, densely disposed spines, with one to four points, posteriorly (Fig. 13); posterior margin of sixty abdominal segment with elon- gated, slender spines; anterior margin of seventh segment with one. or two pointed spines (Fig. 14). Margins of the spiracular cavity covered with long, filamentous spines covering the spiracular tubercles; perianal pads well developed, rounded (Fig. 15); spiracular hairs robust, mostly with two points.

\section{Oxyvinia excisa (Lopes, 1950)}

(Figs. 16 to 25 )

First instar larvae obtained from dissections of female collected in Petrópolis, show very important apomorphies not shared with any other Raviniini hitherto studied. The ribbon of festoons became very slender in midle (Fig. 21),
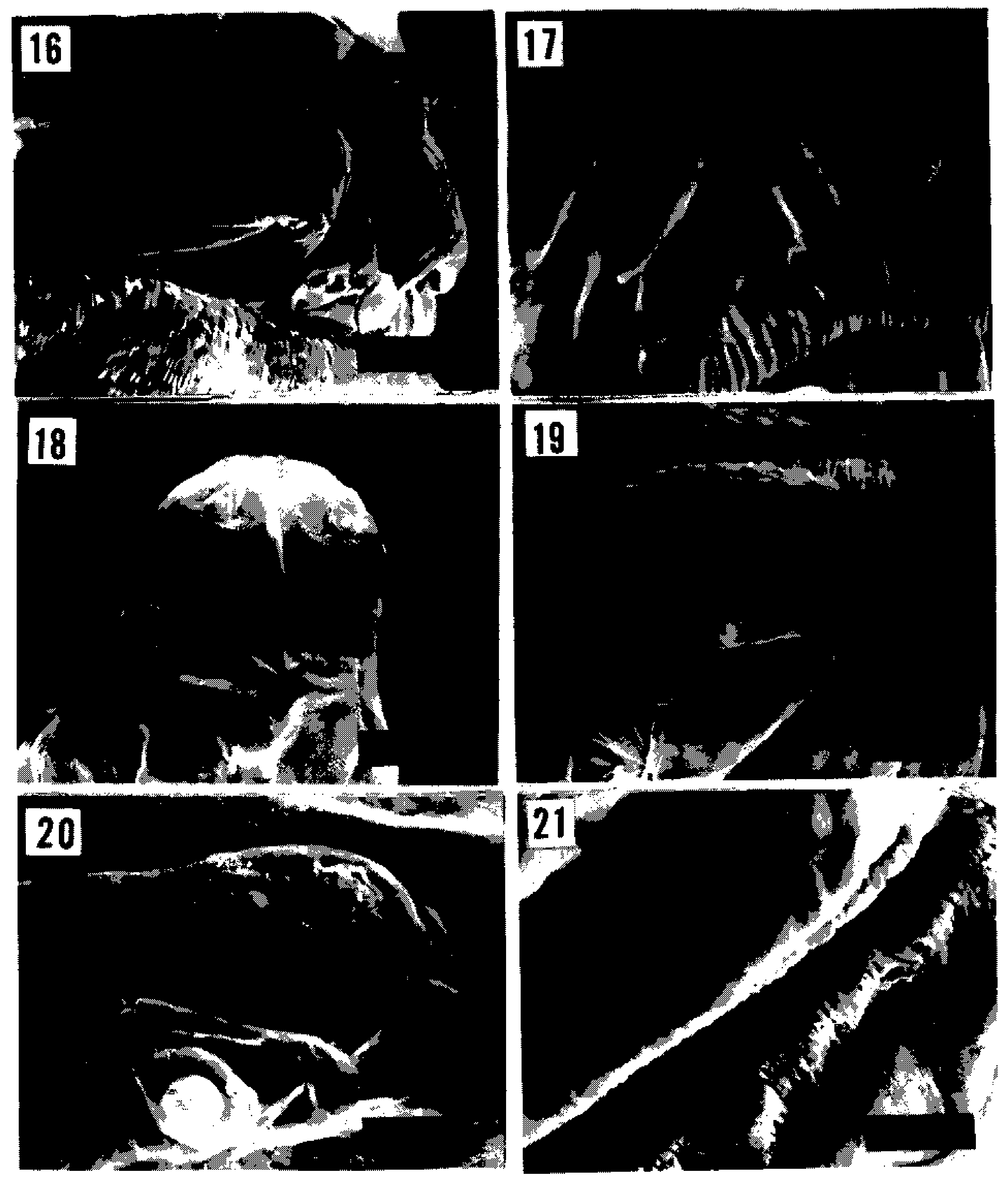

Oxyvinia excisa (Lopes), tirst instar larva. 1.1g. 16: anterıor enu, lateral view. Fig. 17: maxillae and festoons. Fig. 18: anterior end, dorsal view. Fig. 19: festoons, antenna and palpus. Fig. 20: antenna and palpus. Fig. 21 : festoons and spines of first thoracic segment. 
there are conspicuous convex band behind the ribbon of festoons (Figs. 16, 18), the palpus shows some convex mamilliform tubercles (Fig. 20). The convex band and the ribbon of festoons became slender posteriorly (Fig. 18). Ventrally, on the anterior margin of the thoracic segments, long and slender spines, closely inserted, are disposed, directed backwards (Fig. $22)$. On the abdominal segments there are plates with one to four spines (Figs. 23, 24). The margins of the spiracular cavity are densely covered with long hairs, the tubercles not conspicuos; the spiracular hairs, inside the peritema bear three to four points (Fig. 27).

Second instar larvae, obtained from culture on milk cream, present three antenal stages, the last mamilliform; the ventral side of the pseudocephalon shows an apical region composed of irregular small plates and there are numerous parellel striae with small dentations, from the sides of buccal opening (Fig. 28); region of the spiracular cavity densely covered with long hairs, the tubercles conspicuous, anal pads very large (Fig. 29).
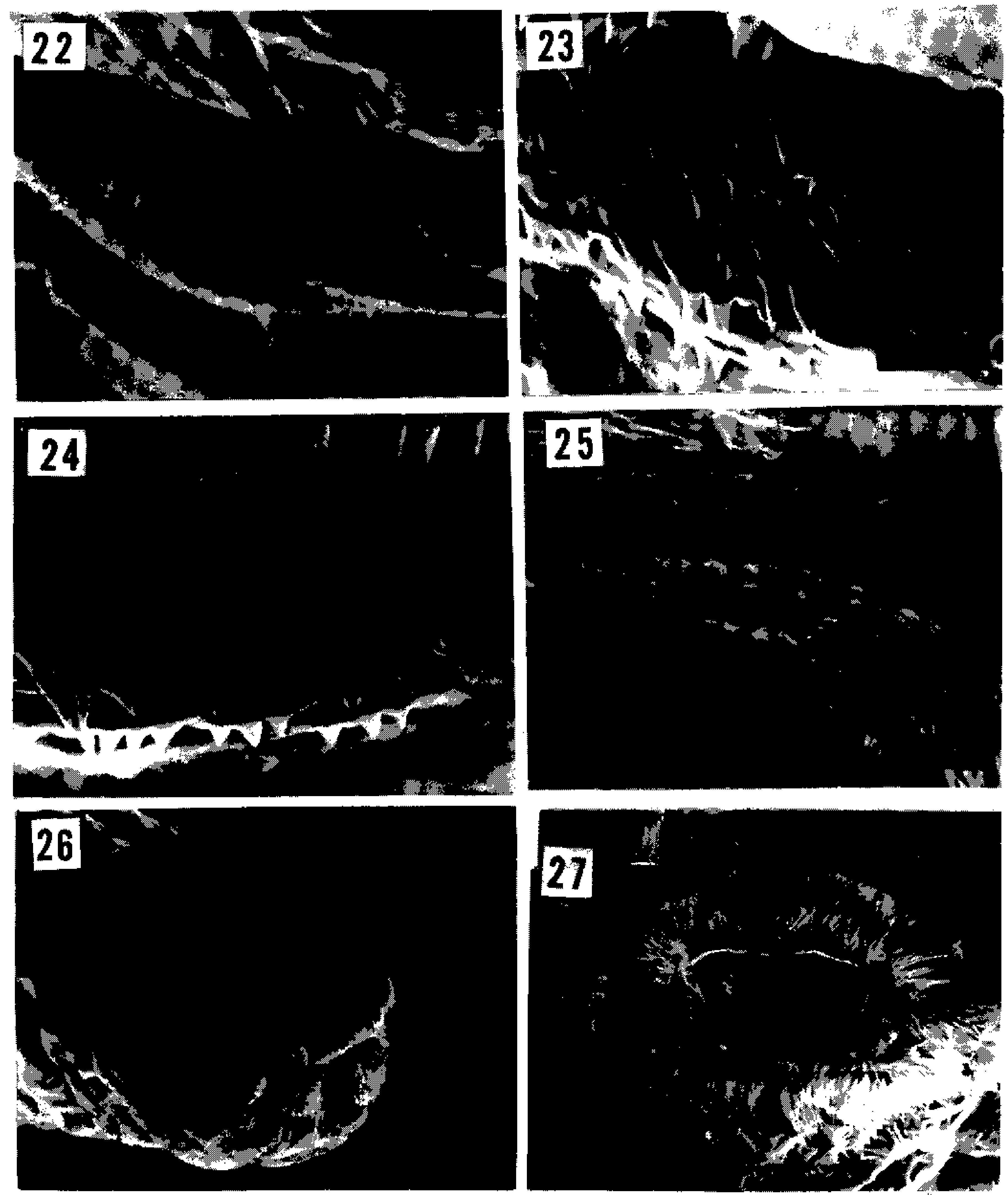

Oxyvinia excisa (Lopes), fürst instar larva. Fig. 22: spines of second thoracic segment. lig. 23: spines of second thoracic segment. Fig. 24 : spines of second abdominal segment. Fig. $25:$ spines of fourth abdominal (above) and fiftl: abdominal segments (below). Fig. 26: posterior end. Fig. 27: stigmatical cavity. 


\section{Oxysarcodexia confusa Lopes, 1944}

(Figs. 26 to 33 )

Second instar larvae: Pseudocephalon bearing palpi composed of a median circular region with few papillae and, around it, concentric elongated plates (Fig. 31); from the oral margins there are parallel striae with small posterior dentations; between the striae and palpi, a group of conspicuos plates, similar to these found in the second instar of Oxyvinia excisa (Lopes), are present. Labial lobe corrugated (Fig. 30). These features demonstrate the close relationship be tween Oxysarcodexia and Oxyvinia.

First thoracic segment with numerous plates bearing two to five spines, directed backwards on anterior margin, ventrally (Fig. 33); the sensilla of the segments are similat to these described for Chaetoravinia almeidai Lopes; anterior spiracles with 10-12 openings (Fig. 32); second and third segments with similar spinous plates, second with some plates bearing a single spine anteriorly; the plates with two spines being rare on third segment; first to seventh abdominal segments with backwards directed strong spines on anterior margins which are slender with filitorm apices, on median third and directed anteriorly on the posterior third (Fig. 34). Papilliform tubercles with spines are present from fifth to seventh segments (Fig. 35). The spines of first segment are smaller and less numerous than these of the following segments. Eigth segment with densely disposed long hairs, covering specially the margins of the spiracular cavity; tubercles well developed, only inner dorsal and inner ventral ones are reduced; anal pads large with pointed extremities, two pairs of anal papillae are scarcely seen; dorsally, between spiracular openings there are 4.5 spiracular hairs, on external side of the openings, and between them two groups of hairs bearing each 3-5 points (Figs. 36, 37).

\section{RESUMO}

Segunda contribuição ao conhecimento das larvas de Raviniini (Diptera, Sarcophagidae) baseada em observaçôes com microscópio eletrônico de varredura - Primeiro e segundo "instars" de Sarcophagidae (Diptera) da tribu Raviniini são descritos neste traballı.

Palivras-chave: 10 a 29 "instars". Sarcophagidae Raviniini - observações ao microscópico de varredura
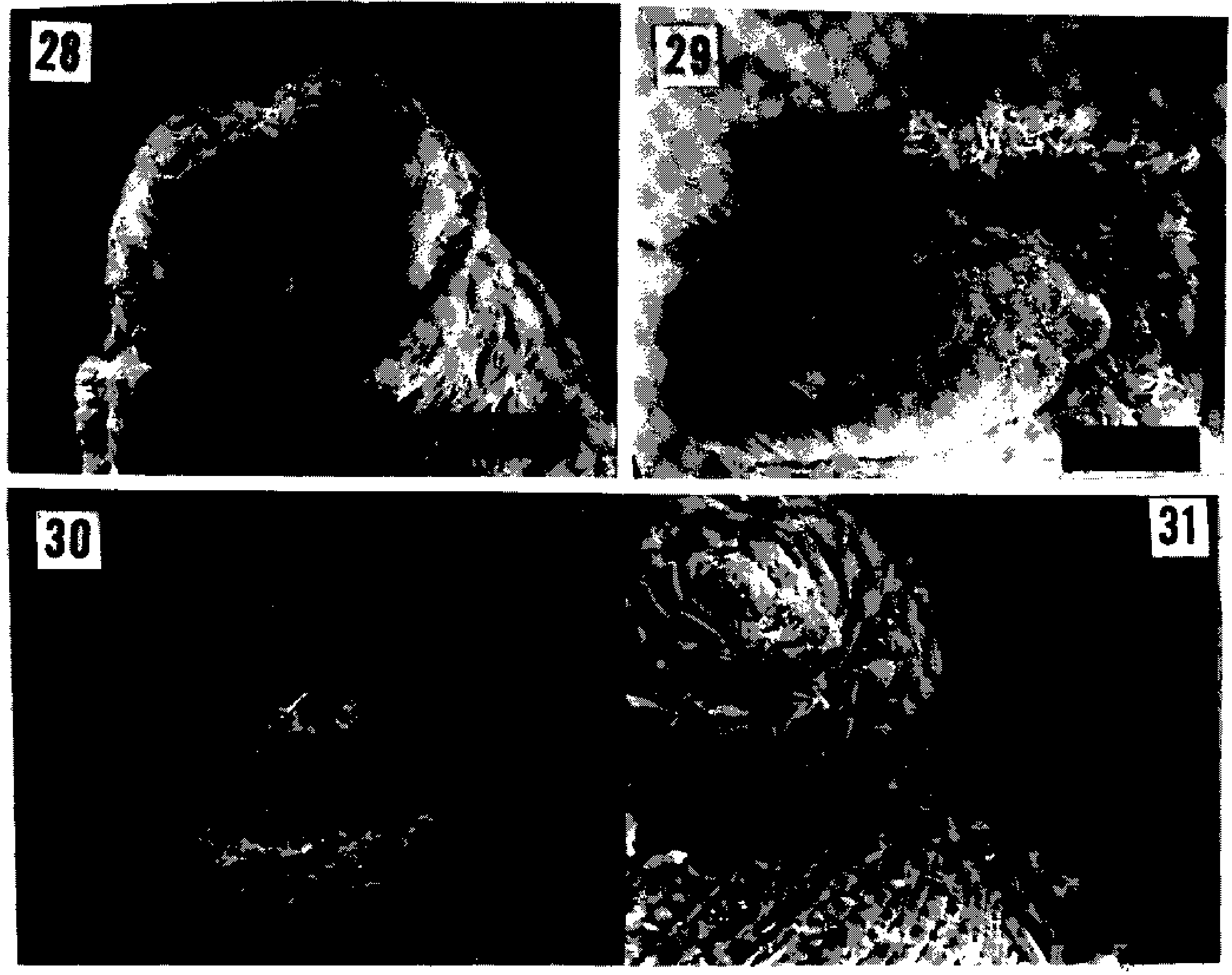

Oxyvinia excisa Lopes, second instar larva. Fig. 28: anterior end, ventral view. Fig. 29: posterior end. Oxysarcodexia confusa Lopes, second instar larva. Jiig. 30 : anterior end, ventral view. Fig. 31 : palpus, plates and furrows. 


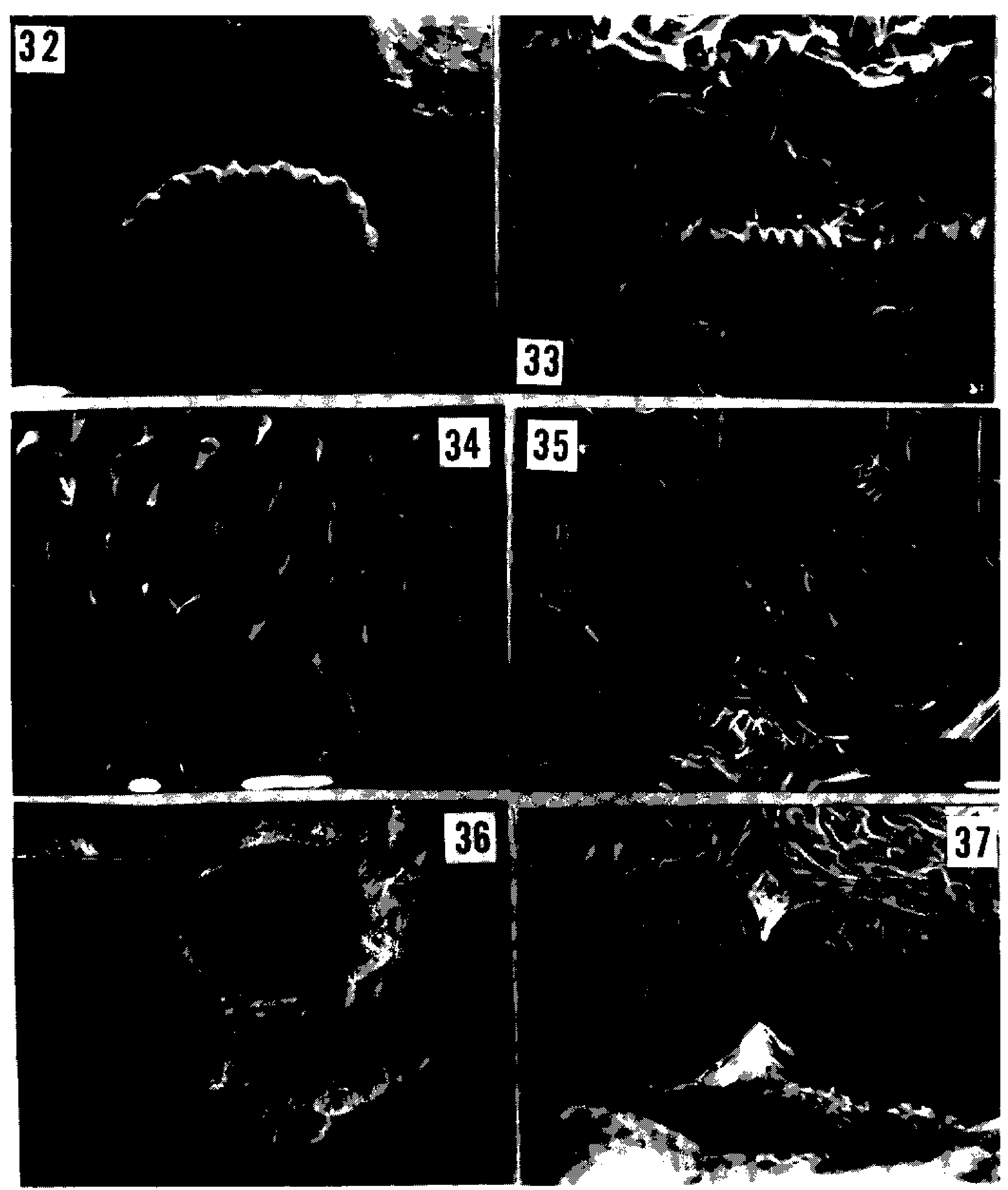

Oxysarcodexia confusa Lopes, second instar larva. Fig. 32: anterior spiracles. Fig. 33: anterior spines of ventral side of first thoracic segment. Fig. $34:$ anterior spines of third abdominal segment. Fig. $35:$ spines and spinous tubercles of sixth abdominal segment. Fig. 36: posterior end. Fig. 37: posterior spiracles.

\section{RIFIERINCES}

DOWNES, W.L., 1965. Sarcophagidae p. 933-961. In A. Stone et al., $A$ catalogue of the Diptera of $A$ merica North of Mexico, Agricultural Research Service, US Dep. Agric., Washington, DC.

LOPES, H.S., 1962. Sobre as espécies de Andinoravinia (Diptera, Sarcophagidac). Mem. Inst. Oswaldo Cruz, $60(2): 165-173,26$ figs.

LOPES, H.S., 1969. A catalogue of the Diptera of the
Americas, South of the United States. 103. Sarcophagidae. S. Paulo, 88 p.

LOPES, H.S., 1978. On Aulacophyto Townsend and Aulacophytoides n. gen. (Diptera, Sarcophagidae). Revta. Brasil. Biol, 38 (4) :757-766, 54 figs.

LOPES, H.S. \& A.C.R. LEITE. Studies on some features of the first instar larvae of Oxysarcodexia (Diptera, Sarcophagidae) based on scanning electron miocroscope observations. Revta. Brasil. Biol. (in press). 